\title{
The effect of resistance training without balance exercises on
} static balance skill

\author{
Mehmet Soyal ${ }^{1 \mathrm{ADE}}$, Aydın Pekel $^{2 \mathrm{BC}}$, Ömür Gülfirat ${ }^{3 \mathrm{ADE}}$ \\ 1,3Istanbul Gelişim University, Turkey \\ ${ }^{2}$ Muğla Sitkı Koçman University,
}

Authors' Contribution: A - Study design; B - Data collection; C - Statistical analysis; D - Manuscript Preparation; E - Funds Collection.

\begin{abstract}
Purpose: $\quad$ The aim is to evaluate the effect of resistance training without balance exercises on the static balance skill.

Material: $\quad$ The universe of the study consists of volunteer students who are chosen among the students with similar physical characteristics and training history $(n=15)$ who are taking education at Istanbul Gelisim University, High School of Physical Education and Sports $(n=1286)$ who have any current health problems and disability history. An information form questionnaire (age, height, and weight, training history) was applied as a personal data collection tool. Static balance skill of the participants tested through AC International East Sp. Z O.O. which has the brand of- SIGMA Balance Platform which is found at performance measurement and evaluation laboratory of Istanbul Gelisim University, High School of Physical Education and Sports. Test procedures were applied before and after the 6-week resistance training program.

Results: $\quad$ Statistically significant differences were detected in test values of Static balance skill $x$ axis deviation rate of the study group, rate of deviation from the center in the $x$ axis, the length of distance and average surface area which is used $(P<0,05)$.

Conclusions: It was identified that 6-week resistance training practices without balance exercises have a positive effect on the development of static balance skill.

Keywords: $\quad$ static balance, resistance training, fitness, static exercises.
\end{abstract}

\section{Introduction}

The purpose of fitness activities is to contribute to the physical and physiological development of the people and to provide them a healthier appearance. Although there are many fitness training methods available today, the aim is to develop strength in most of them. Resistance exercises are one of these practices. The effect of resistance exercise on muscle strength and force is clearly documented [1, 2]. Free weight exercises and stability / balance exercise practices are considered as the most advantageous training methods by the fitness community due to their positive effects on neuromuscular function.

The application of stability / balance exercises and resistance exercises separately or jointly causes positive effects especially on somatosensory disorders [3]. Awareness of the subject is increasing with the understanding of the importance of all actions and related elements of the muscular system in the protection of the posture and the optimal function of the movement system $[4,5]$. Balance can be defined as the central nervous system input from proprioceptive, vestibular and visual afferent nerve signals by analysis of signal integration as an important function in human daily life and sports activities. The human body posture is controlled by motor neurons that regulate muscle activity $[6,7]$. Static stability means that the body position can be maintained at rest [8]. Postural control can be divided into two as static balance and dynamic balance. Static balance controls the oscillation amplitude of the body while dynamic balance uses the internal and external information of the body to analyse factors that affect the balance of the interference (such as walking, pushing and pulling), and maintain postural control. The perfect combination of static and dynamic balance is the key to normal activities of people's daily lives [9].

Fatigue, age, gender, physical activity ability, and lower limb injury are pointed out as the factors that potentially affect postural balance. Single and double foot support, oscillation path under dynamic or static gravitational conditions, and knee lifting for dynamic balance (proprioception) ability are listed as the most commonly used methods to assess the balance ability of the knee joint $[10,11]$. The content of resistance training is formed by high-intensity exercises of anaerobic type. Strength which is the primary element of resistance training is one of the most important bio motor skills for both professional and recreational athletes. High-intensity strength exercises are performed in resistance training. Strength development is expected from $25 \%$ to $100 \%$ with high-intensity strength training [12].

Resistance training is a commonly used exercise that is frequently preferred to improve the physical fitness of individuals. The main goal of resistance training is to achieve hypertrophy by increasing muscle strength and muscle cross-sectional area. Wide variety of training systems created with different combinations of training items such as load intensity, number of sets, number of repetitions, rest interval is used for these purposes [13]. It is assumed that strength which is one of the important neuro motor skills affect many skills related to physical 
fitness. Although balance skill is one of these features, the relationship between power and strength is searched in only a few studies [3]. In addition to resistance training, stability or balance exercise protocols have been applied together in existing studies. Studies show that resistance training practices without balance exercises also have a positive effect on balance development [5].

Hypothesis: It is expected that resistance training without balance exercises will have a positive effect on the static balance skill.

Purpose: It is the evaluation of the effect of resistance training without balance exercises on the static balance skill.

\section{Material and Methods}

Participants. Forming Voluntary Groups: The research group in this study consists of volunteer students who are chosen among the students with similar physical characteristics and training history $(n=15)$ who are taking education at Istanbul Gelisim University, High school of Physical Education and Sports $(n=1286)$ who have any current health problems and disability history. Age, height, $\mathrm{kg}$, health and training history information of the participants were acquired by the survey method. Age range of participants is $21-28$, height range is 171-
$190 \mathrm{~cm}$ and weight range is $67-103 \mathrm{~kg}$. Also this study is limited with participants who use their right foot dominantly.

Research Design. Our study is experimental studies which evaluate the effect of resistance training without static exercises on the static balance skill. The data were collected by applying repeated measurements (pre-testpost-test) technique before and after the strength training program which is applied for 6 weeks for the purpose of the study.

Measurements and Procedures. Gender, age, height, weight, training history and health information of the participants were determined in the descriptive form created by the researcher. Static balance skill of the participants tested through AC International East Sp. Z O.O. which has the brand of- SIGMA Balance Platform which is found at performance measurement and evaluation laboratory of Istanbul Gelisim University, High School of Physical Education and Sports. After making the necessary explanations about the test to the participants, their balance measurements were recorded as eyes open, on both legs and standing with stabile metric test application on the platform with XL (easiest) foot attached for 30 seconds and on one axis on SIGMA Balance Platform by giving one trial right. As a result

Table 1. Resistance Training Program

\begin{tabular}{|c|c|c|c|c|c|}
\hline Warm-Up - Isinma & Sets-Reps & Time & Intensity & Rest & Notes \\
\hline 1.Smr: Calves, It Band, Adductors & 1 & & & & \\
\hline $\begin{array}{l}\text { 2.Cardio: Eliptical Trainer } \\
\text { 3.Static Stretching: Calves, Hip } \\
\text { Flexor, Lats } \\
\text { Cool-Down }\end{array}$ & 1 & $\begin{array}{l}5 \mathrm{Min} . \\
30 \mathrm{Sec} .\end{array}$ & & & \\
\hline Post-Workout Flexibility & \multicolumn{5}{|c|}{ Static Stretching: Calves, Adductors, Hip Flexors, Pectorals } \\
\hline Strength & Sets-Reps & Time & Intensity & Tempo & $\begin{array}{l}\text { Rest } \\
\text { Notes }\end{array}$ \\
\hline \multicolumn{6}{|l|}{ Exercises } \\
\hline \multicolumn{6}{|l|}{ Chest - Back } \\
\hline Standing Cable Chest Press & $1-3$ & $12-20$ & $60-70 \%$ & $4-2-1$ & 0 \\
\hline Standing Cable Row & $1-3$ & $12-20$ & $60-70 \%$ & $4-2-1$ & $\begin{array}{l}\text { Circut } \\
\text { Training }\end{array}$ \\
\hline \multicolumn{6}{|l|}{ Shoulders } \\
\hline $\begin{array}{l}\text { Standing Dumbell Shoulder Press } \\
\text { Biceps-Triceps (Optional) }\end{array}$ & $1-3$ & $12-20$ & $60-70 \%$ & $4-2-1$ & 0 \\
\hline Barbell Curl & $1-3$ & $12-20$ & $60-70 \%$ & $4-2-1$ & \\
\hline Push Down & $1-3$ & $12-20$ & $60-70 \%$ & $4-2-1$ & Super Set \\
\hline \multicolumn{6}{|l|}{ Legs } \\
\hline Step-Up To Balance & $1-3$ & $12-20$ & $60-70 \%$ & $4-2-1$ & $90 \mathrm{Sec}$. \\
\hline \multicolumn{6}{|l|}{ Training Progressive } \\
\hline \multirow{6}{*}{ Strength } & & 1.Week & 2. Week & 3. Week & 4. Week \\
\hline & Sets & $1-2$ & 2 & 3 & 3 \\
\hline & Reps & 20 & 15 & 15 & 12 \\
\hline & Intensity & $60 \%$ & $65 \%$ & $65 \%$ & $70 \%$ \\
\hline & & 5. Week & 6. Week & & \\
\hline & Sets & $1-2$ & 2 & & \\
\hline \multirow[t]{2}{*}{ Strength } & Reps & 20 & 15 & & \\
\hline & Intensity & $60 \%$ & $65 \%$ & & \\
\hline
\end{tabular}


of the measurement, the average deviation rates of the participants from the center of the platform towards the $\mathrm{x}$ axis is determined as $\mathrm{cm}$, also the average deviation speeds towards the $\mathrm{x}$ axis is recorded as $\mathrm{cm}$ and the distance which is used recorded as $\mathrm{cm}$. However, the surface area which is used is determined as $\mathrm{cm}^{2}$.

The general aim of the training program which will be implemented by the study group is to develop strength and increase lean muscle mass. Also, since this training program is designed for people with a regular training background and a good level of fitness, people who meet these criteria are selected. The study was conducted on a voluntary basis by giving information about the training program and measurements to the research group.

The training program was carried out 2 days in a week through 6 weeks in total. Exercises only for strength development which did not contain balance movements were performed in the main phase of the training program. Before training, first; SMR application to calf, IT band and adductor muscle groups in 20-30 seconds, then Cardio work done with elliptical trainer for 5 minutes. Finally calf, hip flexors and back muscles are statically stretched and warming up is completed. After the warmup phase, relevant movements were done for the chest and back muscle groups at week 1: Circular training method without rest, With 4-2-1 tempo application, 1-2 sets of 20 reps with $60 \%$ of the maximal force, for arm muscles: with superset training method without rest, With 4-2-1 tempo application,1-2 sets of 20 reps, for shoulder muscles with $60 \%$ of maximal force With 4-2-1 tempo application, 1-2 sets of 20 reps, with $60 \%$ of the maximal force, for the leg muscles; With 4-2-1 tempo application, $1-2$ sets of 20 reps, by giving a rest for 90 seconds with $60 \%$ of the maximal force. The exercise was completed by stretching the calves, adductors, hip flexors, and pectorals muscle groups with the static stretching method in the cooling phase at the end of the training. The set, repeat, tempo, rest, intensity ratios of the exercises applied in the training program are revised regularly every week and the progression of the training is done [14].

Statistical Analysis.

The data obtained were recorded in computer with the package program named IBM SPSS 25.0. Personal information about the candidates was given by determining inventory averages, factor scores, frequency (f) and percentage (\%) values. Parametric and nonparametric distribution states of scores were analysed by examining parametric and non-parametric distribution curves, skewness-kurtosis values. The data show normal distribution. Paired Sample T test was used to compare the pre and posttests of the research group.

\section{Results}

When Table 2 is examined; it has been identified that the average age of the participants is $23.93 \pm 1.75$, the average height of the participants is $179.33 \pm 2.18 \mathrm{~cm}$, and the average body weight of the participants is 86.53 $\pm 2.39 \mathrm{~kg}$.

When Table 3 is examined; the average deviation ratio of pretest static balance skill of the study group on the $\mathrm{x}$-axis is $0.12 \pm 0.07 \mathrm{~cm}$, the average of the deviation speed rate on the $\mathrm{x}$-axis is $0.60 \pm 0.16 \mathrm{~cm} / \mathrm{sec}$, the distance length which is used is $17.42 \pm 4.54 \mathrm{~cm}$ and the average surface area which is used is identified as $0.04 \pm 0.02 \mathrm{~cm}^{2}$.

The average deviation rate of the posttest static balance skill of the study group on the $\mathrm{x}$ axis is $0.06 \pm 0.04 \mathrm{~cm}$, the average deviation rate from the center on the $\mathrm{x}$ axis is $0.47 \pm 0.14 \mathrm{~cm} / \mathrm{sec}$, the distance length which is used is $14.55 \pm 3.41 \mathrm{~cm}$ and the average surface area which used is identified as $0.02 \pm 0.01 \mathrm{~cm}^{2}$.

Table 2. Descriptive Analysis of Age, Height and Body Weight Measurement Values of the Research Group

\begin{tabular}{lll}
\hline Parameters & $\mathbf{n}$ & Mean \pm Sd \\
\hline Age & 15 & $23.93 \pm 1.75$ \\
Height $(\mathbf{c m})$ & 15 & $179.33 \pm 2.18$ \\
Body Weight $(\mathbf{k g})$ & 15 & $86.53 \pm 2.39$ \\
\hline
\end{tabular}

Table 3. Decriptive Analysis of Static Balance Skill Values of the Study Group

\begin{tabular}{|c|c|c|c|}
\hline Test & Parameters & $\mathbf{n}$ & Mean \pm Sd \\
\hline \multirow{4}{*}{ Pre-Test } & The average deviation rate from the center on the $X$ axis $(\mathrm{cm})$ & 15 & $0.12 \pm 0.07$ \\
\hline & $\begin{array}{l}\text { The speed average deviation rate from the center on the } X \text { axis }(\mathrm{cm}) \\
(\mathrm{cm} / \mathrm{sec})\end{array}$ & 15 & $0.60 \pm 0.16$ \\
\hline & Distance length (cm) & 15 & $17.42 \pm 4.54$ \\
\hline & Surface area $\left(\mathrm{cm}^{2}\right)$ & 15 & $0.04 \pm 0.02$ \\
\hline \multirow{4}{*}{ Post- Test } & The average deviation rate from the center on the $X$ axis $(\mathrm{cm})$ & 15 & $0.06 \pm 0.04$ \\
\hline & $\begin{array}{l}\text { The speed average deviation rate from the center on the } X \text { axis }(\mathrm{cm}) \\
(\mathrm{cm} / \mathrm{sec})\end{array}$ & 15 & $0.47 \pm 0.14$ \\
\hline & Distance length (cm) & 15 & $14.55 \pm 3.41$ \\
\hline & Surface area $\left(\mathrm{cm}^{2}\right)$ & 15 & $0.02 \pm 0.01$ \\
\hline
\end{tabular}


Table 4. Comparison of Static Balance Skill Pretest and Posttest Values of the Study Group

\begin{tabular}{|c|c|c|c|c|c|}
\hline Parameters & Test & $\mathbf{n}$ & Mean \pm Sd & $\mathbf{t}$ & $\mathbf{p}$ \\
\hline \multirow{2}{*}{$\begin{array}{l}\text { The average deviation rate from the center on } \\
\text { the } X \text { axis }(\mathrm{cm})\end{array}$} & Pre Test & 15 & $0.12 \pm 0.07$ & \multirow{2}{*}{3.430} & \multirow{2}{*}{$.004 *$} \\
\hline & Post Test & 15 & $0.06 \pm 0.04$ & & \\
\hline \multirow{2}{*}{$\begin{array}{l}\text { The speed average deviation rate from the } \\
\text { center on the } X \text { axis }(\mathrm{cm})(\mathrm{cm} / \mathrm{sec})\end{array}$} & Pre Test & 15 & $0.60 \pm 0.16$ & \multirow{2}{*}{4.428} & \multirow{2}{*}{$.001 *$} \\
\hline & Post Test & 15 & $0.47 \pm 0.14$ & & \\
\hline \multirow{2}{*}{ Distance length (cm) } & Pre Test & 15 & $17.42 \pm 4.54$ & \multirow{2}{*}{3.329} & \multirow{2}{*}{$.005^{*}$} \\
\hline & Post Test & 15 & $14.55 \pm 3.41$ & & \\
\hline \multirow{2}{*}{ Surface area $\left(\mathrm{cm}^{2}\right)$} & Pre Test & 15 & $0.04 \pm 0.02$ & \multirow{2}{*}{3.595} & \multirow{2}{*}{$.003 *$} \\
\hline & Post Test & 15 & $0.02 \pm 0.01$ & & \\
\hline
\end{tabular}

Note: $\mathrm{n}: 15 ; \mathrm{P}<0,05^{*}$; The average deviation rate from the center on the $X$ axis $(\mathrm{cm}):(t: 3,430 ; p=, 004)$; The speed average deviation rate from the center on the $X$ axis $(\mathrm{cm} / \mathrm{sec})(t: 4,428 ; p=, 001)$; Distance length $(\mathrm{cm})(\mathrm{t}: 3,329 ; p=, 005)$; Surface area $\left(\mathrm{cm}^{2}\right)(\mathrm{t}: 3,595 ; \mathrm{p}=, 003)$.

When Table 4 is examined, statistically significant difference was detected in static balance skill, deviation rate in $\mathrm{x}$ axis, rate of deviation from the center on the $\mathrm{x}$ axis, distance lengths and averages of surface area which is used in pretest and posttest values $(P<0,05)$.

\section{Discussion}

In our study, the average deviation ratio of the pretest static balance skill of the group on the $\mathrm{x}$ axis is identified as $0,12 \pm 0,07 \mathrm{~cm}$, the speed average deviation rate from the center on the $X$ axis $(\mathrm{cm})(\mathrm{cm} / \mathrm{sec})$ is $0,60 \pm 0,16 \mathrm{~cm} /$ $\mathrm{sec}$, the distance length $(\mathrm{cm})$ is $17,42 \pm 4,54 \mathrm{~cm}$, the average surface area is $\left(\mathrm{cm}^{2}\right) 0,04 \pm 0,02 \mathrm{~cm}^{2}$.

The average deviation ratio of the post-test static balance skill of the group on the $\mathrm{x}$ axis is identified as $0,06 \pm 0,04 \mathrm{~cm}$, the speed average deviation rate from the center on the $\mathrm{X}$ axis $(\mathrm{cm})(\mathrm{cm} / \mathrm{sec})$ is $0,47 \pm 0,14 \mathrm{~cm} /$ $\mathrm{sec}$, the distance length $(\mathrm{cm}) 14,55 \pm 3,41 \mathrm{~cm}$, the average surface area is $0,02 \pm 0,01 \mathrm{~cm}^{2}$. A statistically significant difference was found in the pretest-posttest data of static balance parameters (deviation rate on the $\mathrm{x}$ axis, the rate of deviation speed from the center on the $\mathrm{X}$ axis, the distance length, the average surface area) of six-week resistance training which is implemented to the research group. It is observed that there is an improvement in the balance score of the study group. On the other hand, a significant difference was detected in all pretest and posttest results of static balance skill values. Similar studies are determined in the literature. Heitkamp et al. [15] determined the rate of increase in balance score as $146 \%$ in the study group exercising balance training and $34 \%$ in the study group exercising resistance training in their study.

In another study, Kollmitzer et al. [16] identified that exercise for strengthening the back extensor muscle groups implemented to the research group decreased postural stability on hard surfaces after 1 month, while it was determined that there was no change after balance training.
Eylen et al. [17] concluded that the static and dynamic balance abilities of the players have been improved by increasing the dynamic balance scores of the different strength exercises applied to the volleyball players in their study. Orr $\mathrm{R}$ et al. [18] reached a significant increase in balance performance values of control and experiment groups performing power training in their study. Jae-Ryang Yoon et al. [19] found a significant difference in balance skill practices after pre-test and post-test in all study groups in their study. Eckardt [20] accessed significant differences in balance scores of all groups performing lower extremity resistance exercises in unstable areas in his work. It is proven that the studies in the literature are similar to the research findings.

\section{Conclusions}

It was determined that resistance training practices without balance exercises had a positive effect on the development of static balance skill. Although a large number of authors have studied the effects of balance training which are implemented instead of strength training on balance development, few studies have examined the effects of static or dynamic balance exercise programs on performance individually or in combination. More specific studies should be carried out in the field due to the fact that there are too many parameters that are thought to affect the balance-strength relationship. This relationship has been evaluated from a different perspective in our study. Moreover, the relationship between strength and static-dynamic balance exercises can be defined from different aspects with similar studies. It is concluded that this study contributed to the related literature and strength and conditioning specialist, people who train for health in the process of preparing strength and balance training which is one of the popular fitness exercises.

\section{Conflicts of Interest}

The authors declare no conflict of interest. 


\section{References}

1. Hortobagyi T, De Vita P. Favorable neuromuscular and cardiovascular responses to 7 days of exercise with an eccentric overload in elderly women. $J$ Gerontol Biol Sci Med. 2002; 55 (8): B401-10. https://doi.org/10.1093/gerona/55.8.B401

2. Hakkinen K, Newton RU, Gordon SE, McCormick M, Volek JS, Nindl BC, et al. Changes in Muscle Morphology, Electromyographic Activity, and Force Production Characteristics During Progressive Strength Training in Young and Older Men. The Journals of Gerontology Series A: Biological Sciences and Medical Sciences, 1998;53A:B415-23. https://doi.org/10.1093/gerona/53A.6.B415

3. Anderson, KG, Behm, DG. The impact of instability resistance training on balance and stability. Sports Medicine, 2005; 35(1): 43-53. https://doi.org/10.2165/00007256-200535010-00004

4. Stokes I, Gardner-Morse M. Strategies used to stabilize the elbow joint challenged by inverted pendulum loading. $J$ Biomech, 2000; 33 (6): 737- 43. https://doi.org/10.1016/S0021-9290(00)00016-6

5. Eloranta V. Coordination of the thigh muscles in static leg extension. Electromyogr Clin Neurophysiol 1989; 29 (4): 227-33.

6. Lord S, Clark R, Webster I. Physiological factors associated with falls in an elderly population. $J$ Am Geriatr Soc, 1991; 39 (12): 1194- 201. https://doi.org/10.1111/j.1532-5415.1991.tb03574.x

7. Alfieri FM, Riberto M, Gatz LS, Ribeiro CP, Lopes JA, Battistella LR. Comparison of multisensory and strength training for postural control in the elderly. Clin Interv Aging, 2012; 7: 119-125. https://doi.org/10.2147/CIA.S27747

8. Woollacott M, Shumway-Cook A. Attention and the control of posture and gait: a review of an emerging area of research. Gait Posture, 2002; 16: 1-14. https://doi.org/10.1016/s0966-6362(01)00156-4

9. Lacour M, Bernard-Demanze L, Dumitrescu M. Posture control, aging, and attention resources: Models and postureanalysis methods. Neurophysiol Clin, 2008; 38: 411-421. https://doi.org/10.1016/j.neucli.2008.09.005

10. Shashank MD, Ishan G. Effects of joint stabilizers on proprioception and stability- a systematic review and meta-analysis. Phys Ther Sport, 2016; 21: 64-68. https://doi.org/10.1016/j.ptsp.2016.05.006
11.Fridén T, Roberts D, Ageberg E, Waldén $M$, Zätterström R. Review of knee proprioception and the relation to extremity function after an anterior cruciate ligament rupture. J Orthop Sports Phys Ther, 2001; 31: 567-576. https://doi.org/10.2519/jospt.2001.31.10.567

12.Sanchis MJ, Idoate F, Dorado, C, Alayon S, Calbet JA. Large asymmetric hypertrophy of rectus abdominis muscle in professional tennis players. PLoS One, 2010; 5(12). https://doi.org/10.1371/journal.pone.0015858

13.Baechle TR, Earle RW, Wathen D. Resistance training In: Baechle TR, Earle RW (eds). Essentials of strength training and conditioning. Hong Kong: Human Kinetics; 2000.

14.Clark MA. Optimum performance training for the health and fitness professional. USA: National Academy of Sports Medicine; 2004.

15.Heitkamp HC, Horstmann T, Mayer F, Weller J, Dickhuth HH. Gain in strength and muscular balance after balance training. Int J Sports Med, 2001; 22 (4): 285-90. https://doi.org/10.1055/s-2001-13819

16.Kollmitzer J, Ebenbichler G, Sabo A, Kerschan K, Bochdansky T. Effects of back extensor strength training versus balance training on postural control. Med Sci Sports Exerc, 2000; 32 (10): 1770-6. https://doi.org/10.1097/00005768-200010000-00017

17.Eylen MA, Dağlığlu Ö., Gücenmez E. The effects of different strength training on static and dynamic balance ability of volleyball players. Journal of Education and Training Studies, 2017; 5(13): 13-17. https://doi.org/10.11114/jets.v5i13.2881

18.OrrR,DeVosNJ,SinghNA,RossD.A.,StavrinosTM,FiataroneSingh M.A. Power training improves balance in healthy older adults. J Gerontol A Biol Sci Med Sci, 2006; 61(1): 78-85. https://doi.org/10.1093/gerona/61.1.78

19.Jae-Ryang Y, Gi-ChulH, Seol-Jung K, Kwang-JunK.Effects of 12-week resistance exercise and interval training on the skeletal muscle area, physical fitness and mental health in old women. Journal of Exercise Rehabilitation, 2019;15(6):839-847. https://doi.org/10.12965/jer.1938644.322

20.Nils E. Lower-extremity resistance training on unstable surfaces improves proxies of muscle strength, power and balance in healthy older adults: a randomised control trial. Eckardt BMC Geriatrics,2016; 16(1): 2-15. https://doi.org/10.1186/s12877-016-0366-3 


\section{Information about the authors:}

Mehmet Soyal; http://orcid.org/0000-0001-6528-0275; msoyal@gelisim.edu.tr; Istanbul Gelisim University High School of Physical Education and Sports, Istanbul, Turkey.

Aydın Pekel; (Corresponding Author); http://orcid.org/0000-0003-0238-1081; apekel@gelisim.edu.tr.; Muğla Sıtkı Koçman University, Health Sciences Institute Department of Physical Education and Sports, Turkey.

Ömür Gülfirat; http://orcid.org/0000-0003-1664-8664; ogulfirat@gelisim.edu.tr; İstanbul Gelisim University, Vocational High School, Istanbul, Turkey.

\section{Cite this article as:}

Mehmet Soyal, Aydın Pekel, Ömür Gülfirat.The effect of resistance training without balance exercises on static balance skill. Physical Education of Students, 2020;24(3):168-173. https://doi.org/10.15561/20755279.2020.0307

This is an Open Access article distributed under the terms of the Creative Commons Attribution License, which permits unrestricted use, distribution, and reproduction in any medium, provided the original work is properly cited http://creativecommons.org/licenses/by/4.0/deed.en

Received: 15.02 .2020

Accepted: 20.03.2020; Published: 30.06 .2020 